\title{
How to Improve the Diagnostic Accuracy of EUS-FNA in Abdominal and Mediastinal Lymphadenopathy?
}

\author{
Tae Hyeon Kim \\ Department of Internal Medicine, Wonkwang University College of Medicine and Hospital, Iksan, Korea
}

See "Predictive Factors for Inaccurate Diagnosis of Swollen Lymph Nodes in Endoscopic Ultrasound-Guided Fine Needle Aspiration" by Yuki Fujii, Yoshihide Kanno, Shinsuke Koshita, et al., on page 152-158.

In this issue of Clinical Endoscopy, the article by Fujii et al. describes the potential usefulness of endoscopic ultrasound-fine needle aspiration (EUS-FNA) for the evaluation of abdominal and mediastinal lymph nodes (LNs), although just six patients with mediastinal LNs were enrolled. ${ }^{1}$ To achieve a high diagnostic yield from EUS-FNA in these LNs, we should consider many issues such as needle size, the use of stylet and suction, the number of passes, the presence of an on-site cytopathologist, the location and size of LNs, and so on. Some of these issues are still being debated although many articles have been published on them. Although these were not significant predictive factors for inaccurate diagnosis using EUSFNA without rapid on-site cytopathological evaluation in this article, only the LN size $<16 \mathrm{~mm}$ was significant. Primary discrimination of LNs might be helpful to increase the diagnostic value of the FNA cytology.

Intra-abdominal and mediastinal lymphadenopathies may be associated with numerous benign or malignant lesions. Benign lymphadenopathy may occur in response to tuberculosis, fungus, virus, bacteria, connective tissue disease, Castleman's disease, and Wegener's granulomatosis. ${ }^{2}$ Malignant

Received: February 13, 2019 Revised: March 12, 2019

Accepted: March 13, 2019

Correspondence: Tae Hyeon Kim

Department of Internal Medicine, Wonkwang University College of Medicine and Hospital, 895 Muwang-ro, Iksan 54538, Korea

Tel: +82-63-859-2670, Fax: +82-63-855-2025, E-mail: kth@wku.ac.kr ORCID: https://orcid.org/0000-0002-9723-2136

(c) This is an Open Access article distributed under the terms of the Creative Commons Attribution Non-Commercial License (http://creativecommons.org/ licenses/by-nc/3.0) which permits unrestricted non-commercial use, distribution, and reproduction in any medium, provided the original work is properly cited. lymphadenopathy may be developed in lymphoproliferative diseases such as Hodgkin's and non-Hodgkin's lymphomas as well as in variable malignant tumors that have spread to regional LNs, including thyroid, esophageal, lung, biliary, and pancreatic carcinomas. ${ }^{3}$ Diagnosing unclear LN enlargements in the abdomen and mediastinum is important for the accurate diagnosis, staging, and treatment of intra-abdominal and mediastinal diseases by EUS-FNA. ${ }^{4}$ Metastasis of para-aortic LNs in patients with pancreatobiliary cancer has been known as a significant predictive factor of unfavorable prognosis. Preoperative pathologic diagnosis of para-aortic LNs may aid in the surgeon's decision for avoiding overtreatment.

Discrimination between malignant and benign LNs by computed tomography (CT) and magnetic resonance imaging depends mainly on size, shape, and topographic distribution. However, diagnostic accuracy of these cross-sectional imaging modalities is low in the differentiation of benign and malignant LNs. ${ }^{5}$ The specificity of diagnostic EUS for metastatic LNs in pancreatic cancer is approximately $70 \%$. The typical features of EUS in metastatic LNs include size $>1 \mathrm{~cm}$, hypoechogenicity, round shape, and clear margins. However, the results of similar studies did not always support these criteria. ${ }^{6,7}$ The combination of EUS-FNA and radiologic evaluation of LNs may increase the specificity. Some studies have demonstrated that EUS-FNA has a sensitivity of 79\%-98\%, a specificity of $98 \%-100 \%$, and an accuracy of $84 \%-99 \%$ in diagnosing mediastinal and intra-abdominal lymphadenopathies. ${ }^{8,9}$ Ogita et al., in a meta-analysis, evaluated the sensitivity, specificity, positive, and negative predictive value of EUS with FNA in staging lung cancers. ${ }^{10}$ This study demonstrated that the diag- 
nostic accuracy of EUS-FNA was superior to mediastinoscopy, CT, and positron-emission tomography. Moreover, Fujii et al. reported that specificity was very high (94\%). ${ }^{1}$ In addition, other studies have reported the usefulness of elastography and contrast-enhanced harmonic mode to distinguish between malignant and benign LNs. ${ }^{11,12}$

These studies reporting high diagnostic accuracy have some limitations. Most endosonographers have usually performed EUS-FNA on the LNs that have typical metastatic characteristics. As discussed by Fujii et al. in this article, LNs $>16 \mathrm{~mm}$ may have increased diagnostic yield. ${ }^{1}$ This point may lead to biased evaluations of intra-abdominal and mediastinal LNs. Among many LNs in patients with malignant tumors, choosing which LNs to use for EUS-FNA may be challenging because small LNs $<5 \mathrm{~mm}$ may contain occult foci of carcinoma. Malignant cell infiltration occurs in up to $30 \%$ of LNs of $<5$ $\mathrm{mm}$, which has been shown for pulmonary and gastrointestinal carcinoma. ${ }^{13}$ Another important limitation is that these studies were performed by expert endosonographers.

It seems particularly difficult for EUS-FNA to diagnose lymphoproliferative disorders that require adequate specimens for a histological examination and further subtyping. Fujii et al. showed that two false-negative cases were diagnosed in patients with malignant lymphoma. ${ }^{1}$ The accuracy of EUS-FNA with flow cytometry in diagnosing lymphoma was $94.2 \%{ }^{5}$ However, operative biopsy to obtain an adequate specimen may be required for the accurate diagnosis and subclassification of Hodgkin's lymphoma by the cytomorphologic and immunophenotypical approaches. ${ }^{14}$ A total of $\geq 3$ passes at various sites in the LNs may be necessary to take adequate samples without necrotic tissue and blood contamination during sampling. One study demonstrated that a larger needle size improved tissue acquisition in EUS-FNA of LNs. ${ }^{15}$

In conclusion, the cytology and histology of EUS-FNA have been established for staging and diagnosing enlarged LNs as well as solid malignant masses in the intra-abdominal and mediastinal areas. The diagnostic accuracy of EUS-FNA is superior to the imaging criteria of EUS and cross-sectional imaging for malignant LNs. EUS-FNA has a low complication rate. Although selecting large LNs for EUS-FNA may increase diagnostic accuracy, it should be carefully evaluated because small LNs may have occult foci of carcinoma. Furthermore, we need to consider the type and size of FNA needles, the number of needle passes, the presence of on-site evaluation, the FNA techniques, and the location of LNs.
Conflicts of Interest

The author has no financial conflicts of interest.

\section{REFERENCES}

1. Fujii Y, Kanno Y, Koshita S, et al. Predictive factors for inaccurate diagnosis of swollen lymph nodes in endoscopic ultrasound-guided fine needle aspiration. Clin Endosc 2019;52:152-158.

2. Bem C, Patil PS, Bharucha H, Namaambo K, Luo N. Importance of human immunodeficiency virus-associated lymphadenopathy and tuberculous lymphadenitis in patients undergoing lymph node biopsy in Zambia. Br J Surg 1996;83:75-78.

3. Pugh JL, Jhala NC, Eloubeidi MA, et al. Diagnosis of deep-seated lymphoma and leukemia by endoscopic ultrasound-guided fine-needle aspiration biopsy. Am J Clin Pathol 2006;125:703-709.

4. Cho JW. The role of endosonography in the staging of gastrointestinal cancers. Clin Endosc 2015;48:297-301.

5. Wang J, Chen Q, Wu X, Wang Y, Hou W, Cheng B. Role of endoscopic ultrasound-guided fine-needle aspiration in evaluating mediastinal and intra-abdominal lymphadenopathies of unknown origin. Oncol Lett 2018;15:6991-6999.

6. Kanamori A, Hirooka Y, Itoh A, et al. Usefulness of contrast-enhanced endoscopic ultrasonography in the differentiation between malignant and benign lymphadenopathy. Am J Gastroenterol 2006;101:45-51.

7. Song HJ, Kim JO, Eun SH, et al. Endoscopic ultrasonograpic findings of benign mediastinal and abdominal lymphadenopathy confirmed by EUS-guided fine needle aspiration. Gut Liver 2007;1:68-73.

8. Chen VK, Eloubeidi MA. Endoscopic ultrasound-guided fine needle aspiration is superior to lymph node echofeatures: a prospective evaluation of mediastinal and peri-intestinal lymphadenopathy. Am J Gastroenterol 2004;99:628-633.

9. Devereaux BM, Leblanc JK, Yousif E, et al. Clinical utility of EUS-guided fine-needle aspiration of mediastinal masses in the absence of known pulmonary malignancy. Gastrointest Endosc 2002;56:397-401.

10. Ogita S, Robbins DH, Blum RH, Harris LJ. Endoscopic ultrasound fine-needle aspiration in the staging of non-small-cell lung cancer. Oncology (Williston Park) 2006;20:1419-1425; discussion 1425-1426, 1431, 1434-1436.

11. Sazuka T, Akai T, Uesato M, et al. Assessment for diagnosis of lymph node metastasis in esophageal cancer using endoscopic ultrasound elastography. Esophagus 2016;13:254-263.

12. Hocke M, Ignee A, Dietrich C. Role of contrast-enhanced endoscopic ultrasound in lymph nodes. Endosc Ultrasound 2017;6:4-11.

13. Cui XW, Jenssen C, Saftoiu A, Ignee A, Dietrich CF. New ultrasound techniques for lymph node evaluation. World J Gastroenterol 2013;19:4850-4860.

14. Meda BA, Buss DH, Woodruff RD, et al. Diagnosis and subclassification of primary and recurrent lymphoma. The usefulness and limitations of combined fine-needle aspiration cytomorphology and flow cytometry. Am J Clin Pathol 2000;113:688-699.

15. Yasuda I, Tsurumi H, Omar S, et al. Endoscopic ultrasound-guided fine-needle aspiration biopsy for lymphadenopathy of unknown origin. Endoscopy 2006;38:919-924. 